\title{
Dual Tracer Stable Isotopic Assessment of Calcium Absorption and Endogenous Fecal Excretion in Low Birth Weight Infants
}

\author{
STEVEN A. ABRAMS, NORA V. ESTEBAN, NANCY E. VIEIRA, AND ALFRED L. YERGEY \\ Laboratory of Theoretical and Physical Biology, National Institute of Child Health and Human Development, \\ Bethesda, Maryland 20892; Holy Cross Hospital, Silver Spring, Maryland 20510; and Children's National \\ Medical Center, Washington, District of Columbia 20010
}

\begin{abstract}
Using a dual tracer $\left({ }^{44} \mathrm{Ca}\right.$ orally and ${ }^{46} \mathrm{Ca}$ i.v.) stable isotope technique, true dietary Ca absorption, endogenous fecal $\mathrm{Ca}$ excretion, and net $\mathrm{Ca}$ retention were measured in 12 low birth weight $(1426 \pm 260 \mathrm{~g})$ infants fed a high Ca-containing formula. Endogenous fecal $\mathrm{Ca}$ excretion averaged $7.2 \pm 4.1 \%$ of intake, and exceeded $10 \%$ of intake in three infants. Net Ca retention, $103 \pm 38$ $\mathrm{mg} / \mathrm{kg} / \mathrm{d}$, was consistent with previous studies of Ca retention obtained using mass balance techniques and correlated closely $(r=0.98, p<0.001)$ with true Ca absorption but not with endogenous fecal excretion $(r=-0.40, p=0.19)$. Although endogenous fecal excretion may represent a significant source of Ca loss for some low birth weight infants, these data suggest that net $\mathrm{Ca}$ retention in low birth weight infants fed a high Ca-containing formula is primarily determined by the total dietary Ca absorbed. (Pediatr Res 29: 615-618, 1991)
\end{abstract}

\section{Abbreviations}

LBW, low birth weight

$V_{f}$, endogenous fecal Ca excretion

$V_{i}, C a$ intake

$V_{\mathrm{a}}$, true dietary $\mathrm{Ca}$ absorption

$V_{u}$, urinary Ca excretion

$\mathrm{V}_{o}$, net $\mathrm{Ca}$ retention (bone accretion)

Numerous recent studies in LBW infants have assessed the bioavailability of $\mathrm{Ca}$ in special formulas containing high concentrations of $\mathrm{Ca}$ relative to human milk. However, these studies have yielded extremely variable results regarding the fractional and total $\mathrm{Ca}$ absorbed and retained (1-8). For example, when different investigators studied essentially the same formula, the net $\mathrm{V}_{\mathrm{o}}$ reported ranged from approximately 80 to $170 \mathrm{mg} / \mathrm{kg} / \mathrm{d}$ $(1,2,4-7)$.

The etiology of the reported variability in Ca retention remains unclear. Minor differences in patient characteristics are likely to be only partly responsible. Differences between investigators in details of the mass balance method do not explain the relatively high coefficients of variation for absorption and retention seen within many studies.

We hypothesized that secretory $\mathrm{Ca}$ losses in the feces, $\mathrm{V}_{f}$, may be substantial in LBW infants $(4,9,10)$ and might explain a significant portion of the variability in reported $\mathrm{Ca}$ balance data. The effect of $V_{f}$ on $V_{0}$ has not been assessed in most previous

Received November 28, 1990; accepted February 18, 1991.

Correspondence: Steven A. Abrams, M.D., 9000 Rockville Pike, LTPB/NICHD, Bldg. 10, Rm. 6C-101, Bethesda, MD 20892. studies of $\mathrm{Ca}$ balance in infants because the mass balance technique does not differentiate between unabsorbed and endogenously excreted fecal $\mathrm{Ca}$.

The use of stable isotopes of $\mathrm{Ca}$ allows for the direct measurement of $V_{f}$ without requiring exposure to ionizing radiation. $V_{a}$ and $V_{f}$ can be determined from the simultaneous administration of both i.v. and oral isotopic tracers with subsequent monitoring of fecal and urinary tracer excretion $(11-17)$. In this study, we used ${ }^{44} \mathrm{Ca}$ and ${ }^{46} \mathrm{Ca}$ to measure $\mathrm{V}_{\mathrm{a}}$ and $\mathrm{V}_{\mathrm{f}}$ in a group of healthy, growing, LBW infants. The objectives of our study were to measure the rates of $V_{a}$ and $V_{f}$ in LBW infants on a fixed, high $\mathrm{Ca}$-containing diet and to determine their relationship to $\mathrm{V}_{\mathrm{o}}$

\section{MATERIALS AND METHODS}

Patient population. Infants admitted to the neonatal intensive care units at Holy Cross Hospital, Silver Spring, MD, and Children's National Medical Center, Washington, DC, who weighed between $750-1750 \mathrm{~g}$ at birth, and whose mothers chose not to breast feed, were eligible for enrollment in this study. A dual tracer stable isotope study, with subsequent 24-h urine and 96-h stool collections, was conducted when the infants were receiving complete enteral nutrition of the designated formula for a minimum of $1 \mathrm{wk}$ and were free of medical illnesses. At the time of the study, all patients were free of ventilatory support, diuretics, and antibiotic therapy. Three infants $(\mathrm{CB}, \mathrm{BH}$, and $\mathrm{RM}$ ) were receiving caffeine. No patient had received steroids postnatally. The study was approved by the Institutional Review Committee of the National Institute of Child Health and Human Development and by the review committees of the respective hospitals. Informed written consent was obtained from the parents prior to enrollment in the study.

Initial feedings were begun at $4 \pm 3 \mathrm{~d}$ (mean $\pm \mathrm{SD}$ ) with feedings of dilute Similac Special Care (Ross Laboratories, Columbus, $\mathrm{OH}$ ) and advanced over a 5- to $10-\mathrm{d}$ period to fullstrength formula at approximately $120 \mathrm{kcal} / \mathrm{kg} / \mathrm{d}$. Formula was provided from ready-to-feed bottles, $24 \mathrm{kcal}$ per fluid ounce in 10 patients and $20 \mathrm{kcal}$ per fluid ounce in two patients. All infants were fed by bottle or intermittent orogastric gavage. Vitamin D $200 \mathrm{IU} / \mathrm{d}$ was given in the form of a multivitamin supplement. Total vitamin D intake of formula plus supplement was approximately $400 \mathrm{IU} / \mathrm{d}$.

Intake and output measurements. Details of the urine and stool collections have been described previously (14-17). Eighteen $\mathrm{h}$ before the beginning of the study, one-half volume of a single feeding was mixed with $1.5 \mathrm{mg} / \mathrm{kg}$ of ${ }^{44} \mathrm{Ca}$ and refrigerated at $-4^{\circ} \mathrm{C}$ overnight. The following morning, the infants were given $0.015 \mathrm{mg} / \mathrm{kg}$ of ${ }^{46} \mathrm{Ca}$ i.v. over $5-10 \mathrm{~min}$. Subsequently, the premixed feeding with the added ${ }^{44} \mathrm{Ca}$ was fed orally or via orogastric tube. The remainder of the volume of that feeding was added to the syringe (for tube feedings), or bottle, and given to 
the infants. Samples of the formula and the formula mixed with tracer were collected before feeding. After the single feeding, any residual formula in the bottle or syringe/tubing was collected. The formula samples were analyzed for total $\mathrm{Ca}$ and $\mathrm{Ca}$ isotope ratios. From these measurements, the total tracer remaining in the bottle, or syringe/tubing was calculated to determine the actual doses of tracer administered (16).

Immediately after the ${ }^{46} \mathrm{Ca}$ infusion, the infants were placed unrestrained on a mesh hammock suspended over a stainless steel metabolic bed within an incubator. Urine was collected in 4-h aliquots in sterile, $\mathrm{Ca}$-free, polypropylene containers for a total of $24 \mathrm{~h}$. Stools were collected individually using sterile polyethylene bags adhered to the buttocks. After $24 \mathrm{~h}$, the infants were removed from the metabolic bed and stools collected in polyethylene bags for an additional $72 \mathrm{~h}$.

Nutrient intake was calculated from the volume of formula ingested and the concentration of $\mathrm{Ca}$ measured in the formula. Any spillage was noted and subtracted from intake. Body weight, length, head circumference, and serum $\mathrm{Ca}$, phosphorus, and alkaline phosphatase activity were measured at the beginning of the study.

Isotope preparation and analytical techniques. Sterile solutions of ${ }^{46} \mathrm{Ca}, 0.37-0.50 \mathrm{mmol} / \mathrm{L}(0.015-0.02 \mathrm{mg} / \mathrm{mL})$ and ${ }^{44} \mathrm{Ca}$, $87.33-162.18 \mathrm{mmol} / \mathrm{L}(3.5-6.5 \mathrm{mg} / \mathrm{mL})$ were prepared by the National Institutes of Health pharmacy and tested for pyrogenicity and sterility before use. $\mathrm{Ca}$ isotopes were obtained from Oak Ridge National Laboratory, Oak Ridge, TN.

Total $\mathrm{Ca}$ was measured on all urine samples by flame atomic absorption spectrophotometry. Stool and formula samples were individually homogenized and an aliquot was ashed using a CEM Microwave Digestion System, model MDS-81D (CEM Corp., Indian Trail, NC) before analysis.

Isotope enrichment was determined using a Finnigan MAT Thermoquad (Bremen, Germany) mass spectrometer. After precipitation of the Ca with ammonium oxalate, each sample was analyzed for the ratio of ${ }^{44} \mathrm{Ca} /{ }^{48} \mathrm{Ca}$ and ${ }^{46} \mathrm{Ca} /{ }^{48} \mathrm{Ca}$. A total of four blocks of 10 scans each were obtained and the median enrichment of the four blocks determined (14-16). The relative SD of this median for enriched samples was $<1 \%$. For nonenriched samples, this technique yields results for the naturally occurring ratios within $1.5 \%$ of the accepted ratio as determined by the National Institute of Standards and Technology (18).

Calculations. The mathematical methods for the calculation of $\mathrm{V}_{\mathrm{a}}$ using a dual tracer stable isotope technique have been described previously (14-16). The dynamics of the system are depicted in Figure 1. The true fractional absorption of $\mathrm{Ca}$ (alpha) is calculated as the ratio of the accumulated oral versus i.v. tracer in urine during the $24 \mathrm{~h}$ after tracer administration.

$$
\text { alpha }=\frac{\int_{0}^{1} \text { oral dose in urine }}{\int_{0}^{\mathrm{t}} \text { i.v. dose in urine }}
$$

$\mathrm{V}_{\mathrm{a}}$ is then calculated from alpha and $\mathrm{V}_{\mathrm{i}}$ as:

$$
\mathrm{V}_{\mathrm{a}}=\text { alpha } \cdot \mathrm{V}_{\mathrm{i}}
$$

The method for the direct calculation of $\mathrm{V}_{\mathrm{f}}$ after bolus administration of an i.v. tracer is adapted from the description of Aubert et al. $(11,12)$ from studies using radiotracers. We have recently described the application of this method to studies in children ( 3 to 14 y of age) using Ca-stable isotopes (17). In this technique, $V_{f}$ and $V_{u}$ are assumed to occur from a single central pool. This pool is believed to consist of plasma and some components of extracellular fluid and surface bone. Ca flow to stable bone from the central pool may involve intermediate, kinetically determined bone pools; however, these do not affect the calculation of $V_{f}$ or $V_{u}(19-21)$. With this assumption, the ratio $V_{f} / V_{u}$ is equal to the ratio of the accumulated tracer

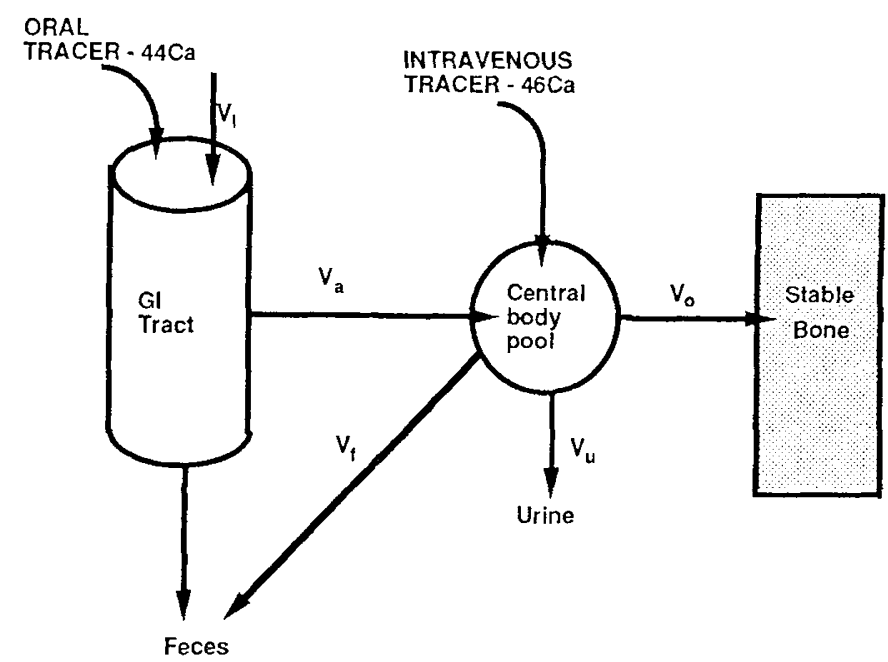

Fig. 1. Model for Ca distribution in LBW infants. The true fraction of dietary $\mathrm{Ca}\left(\mathrm{V}_{i}\right)$ absorbed is represented by $\mathrm{V}_{\mathrm{a}}$. Ca secretion into the gastrointestinal tract may occur at separate sites from absorption. $V_{f}$ represents secretory losses into the stool. Urinary $\mathrm{Ca}$ excretion is shown as $V_{\mathrm{u}}$. Net $\mathrm{Ca}$ retention with transfer to stable bone from a central rapidly exchanging pool (presumed to consist of plasma, extracellular fluid, and surface bone) (21) is represented by $\mathrm{V}_{\mathrm{o}}$. Ca resorption from stable bone in LBW infants is assumed to be negligible during the time course of the study.

recovered in the stool compared to the tracer recovered in the urine. This can be expressed as follows:

$$
V_{\mathrm{f}}=\frac{\int_{0}^{\mathrm{t}} \text { i.v. dose in stool }}{\int_{0}^{\mathrm{t}} \text { i.v. dose in urine }} \cdot V_{\mathrm{u}}
$$

A period of time $(t)$ is chosen such that the recovery of the tracer has neared "completeness," that is, the curve of accumulated tracer recovery has achieved an asymptotic value. From Figure 1 , it can be seen that the net $\mathrm{Ca}$ retained and subsequently transferred to deep bone, $V_{0}$, is equal to the difference between $\mathrm{V}_{\mathrm{a}}$ and the sum of all losses. Assuming negligible dermal losses, this leads to:

$$
\mathrm{V}_{\mathrm{o}}=\mathrm{V}_{\mathrm{a}}-\left(\mathrm{V}_{\mathrm{u}}+\mathrm{V}_{\mathrm{f}}\right)
$$

Relationships among variables were compared by linear regression analysis. All data are expressed as mean \pm SD. Coefficients of variation were calculated as the SD divided by the mean (22).

\section{RESULTS}

Thirteen patients were enrolled in the study. A single infant developed evidence of sepsis during the study and was excluded. Gestational ages, birth weights, body weights, and ages at the time of the study of the remaining 12 patients are shown in Table 1. One infant (MC) was small for gestational age, weighing $1250 \mathrm{~g}$ at birth, 37 wk gestation.

Calcium-stable isotope data for the study infants are shown in Table 2. The results for the small-for-gestational-age infant were similar to the data of the other infants and were included in the analyses. For the 12 study infants, $V_{\mathrm{a}}, \mathrm{V}_{\mathrm{f}}, \mathrm{V}_{\mathrm{u}}$, and $\mathrm{V}_{\mathrm{o}}$ represented $56 \pm 16,7 \pm 4,2 \pm 1$, and $48 \pm 18 \%$, respectively, of dietary $V_{i}$.

$\mathrm{V}_{\mathrm{o}}$ was highly correlated to true fractional and total Ca absorption $\left(r=0.94\right.$ and 0.98 , respectively, $p<0.001$ for each). $V_{o}$ was not significantly correlated to $\mathrm{V}_{f}(r=-0.40, p=0.19)$. There was no significant relationship between $\mathrm{V}_{\mathrm{o}}$ or $\mathrm{V}_{\mathrm{a}}$ and birth weight, gestational age, body weight, $V_{i}$, body length, head circumference, age at study, age at first feed, feeding method, serum $\mathrm{Ca}$, 
Table 1. Study population

\begin{tabular}{lcccc}
\hline Patient & $\begin{array}{c}\text { Gestational } \\
\text { age }(w k)\end{array}$ & $\begin{array}{c}\text { Birth wt } \\
(\mathrm{g})\end{array}$ & $\begin{array}{c}\text { Postnatal } \\
\text { age }(\mathrm{d})\end{array}$ & $\begin{array}{c}\text { Body wt } \\
(\mathrm{g})\end{array}$ \\
\hline CB & 27 & 776 & 41 & 1400 \\
MC & 37 & 1250 & 15 & 1563 \\
SC & 33 & 1710 & 13 & 2000 \\
JE & 33 & 1615 & 16 & 1815 \\
BH & 31 & 1525 & 19 & 1659 \\
RH & 34 & 1640 & 13 & 1835 \\
NL & 30 & 1365 & 25 & 1790 \\
RL & 34 & 1490 & 13 & 1528 \\
KM & 30 & 1404 & 17 & 1696 \\
RM & 31 & 1417 & 22 & 1488 \\
DP & 34 & 1690 & 8 & 1703 \\
PP & 30 & 1228 & 35 & 1841 \\
Mean & 32 & 1426 & 20 & 1693 \\
SD & 3 & 260 & 10 & 174 \\
\hline
\end{tabular}

Table 2. Ca balance in low birth weight infants $(\mathrm{mg} / \mathrm{kg} / \mathrm{d})$

\begin{tabular}{lrrrrr}
\hline Patient & $\mathrm{V}_{\mathrm{i}}$ & $\mathrm{V}_{\mathrm{u}}$ & $\mathrm{V}_{\mathrm{f}}$ & $\mathrm{V}_{\mathrm{u}}$ & $\mathrm{V}_{\mathrm{o}}$ \\
\hline $\mathrm{CB}$ & 189 & 141 & 7 & 3 & 131 \\
$\mathrm{MC}$ & 215 & 120 & 9 & 7 & 104 \\
$\mathrm{SC}$ & 216 & 138 & 13 & 7 & 118 \\
$\mathrm{JE}$ & 216 & 62 & 28 & 2 & 32 \\
$\mathrm{BH}$ & 212 & 133 & 17 & 7 & 109 \\
$\mathrm{RH}$ & 242 & 117 & 8 & 1 & 108 \\
$\mathrm{NL}$ & 209 & 134 & 15 & 6 & 113 \\
$\mathrm{RL}$ & 204 & 124 & 33 & 2 & 89 \\
$\mathrm{KM}$ & 226 & 182 & 7 & 2 & 173 \\
$\mathrm{RM}$ & 226 & 83 & 19 & 2 & 61 \\
$\mathrm{DP}$ & 225 & 160 & 25 & 1 & 134 \\
$\mathrm{PP}$ & 216 & 71 & 7 & 4 & 60 \\
Mean & 216 & 122 & 15 & 4 & 103 \\
SD & 13 & 35 & 9 & 2 & 38 \\
CV & 6 & 29 & 60 & 50 & 37 \\
\hline
\end{tabular}

$* \mathrm{CV}=$ coefficient of variation, expressed as $\%$.

serum phosphorus, alkaline phosphatase activity, or $\mathrm{V}_{\mathrm{u}}(r<0.3$, $p>0.2$ for each).

\section{DISCUSSION}

The dual tracer technique has been demonstrated to be an accurate and reproducible method for evaluating $\mathrm{Ca}$ balance in adults and children $(14,15,21)$. It allows for the calculation of fractional absorption directly from a $24-\mathrm{h}$ urine collection. The use of stable isotopes also eliminates the need for any radiation exposure to the patient. Furthermore, the use of $\mathrm{Ca}$ isotopes allows for kinetic measurements of $\mathrm{Ca}$ dynamics $(18,19,23)$.

Our results indicate that $V_{\circ}$ is primarily related to $V_{a}$, not $V_{f}$. $V_{i}$ represented approximately $7 \%$ of the infants' dietary $V_{i}$ and was much greater than their $\mathrm{V}_{\mathrm{u}}$ (Table 2). This pattern is different from that observed in adults in whom $V_{f}$ is approximately $2 \mathrm{mg} /$ $\mathrm{kg} / \mathrm{d}$ and is usually lower than $\mathrm{V}_{\mathrm{u}}(24)$. The reasons for these higher rates of $V_{f}$ in premature infants are unknown but may be related to gastrointestinal immaturity $(9,21)$.

That $\mathrm{V}_{\mathrm{o}}$ might be related to $\mathrm{V}_{\mathrm{f}}$ was suggested by the study of Barltrop et al. $(9,10)$, in which $\mathrm{V}_{\mathrm{f}}$ varied from $4-150 \mathrm{mg} / \mathrm{kg} / \mathrm{d}$ in premature infants (mean $86 \mathrm{mg} / \mathrm{kg} / \mathrm{d}$ ). However, that study used a single orally administered $\mathrm{Ca}$ isotope, and $\mathrm{V}_{\mathrm{f}}$ was calculated indirectly based on mass balance and fecal isotope recovery data. Using a similar technique, Senterre (25) found much lower rates $(17 \mathrm{mg} / \mathrm{kg} / \mathrm{d})$ for $\mathrm{V}_{\mathrm{f}}$ in LBW infants, as did Moore et al. (20) in a small study $(n=2)$ using an i.v. administered Ca isotope to calculate $\mathrm{V}_{\mathrm{f}}$ directly. The rate of $\mathrm{V}_{\mathrm{f}}$ in $\mathrm{LBW}$ infants in this study, $15.5 \pm 8.9 \mathrm{mg} / \mathrm{kg} / \mathrm{d}$, is similar to the results obtained by Senterre and by Moore et al. and much lower than the rate reported by Barltrop et al.
The three patients in whom $V_{f}$ exceeded $10 \%$ of intake suggest that some LBW infants may have relatively large secretory losses. Because all patients received comparable $V_{i}$, this study did not assess the possible effect of dietary $V_{i}$ on $V_{f}$. However, studies in adults have not shown a close relationship between dietary $V_{i}$ and $V_{\mathrm{f}}(24)$.

The $V_{o}$ for patients in this study, $103 \pm 38 \mathrm{mg} / \mathrm{kg} / \mathrm{d}$, meets the lower estimates of the in utero Ca retention $(100-130 \mathrm{mg} /$ $\mathrm{kg} / \mathrm{d}$ ) during the $3 \mathrm{rd}$ trimester $(10)$. It is below the reports of $130-170 \mathrm{mg} / \mathrm{kg} / \mathrm{d}$ Ca retention $(1,2,5-7)$, but it is somewhat higher than a recent report of approximately $80 \mathrm{mg} / \mathrm{kg} / \mathrm{d}$ retention with this formula (or a similar earlier formulation) (4).

The coefficients of variation for $\mathrm{V}_{\mathrm{a}}, 29 \%$, and for $\mathrm{V}_{\mathrm{o}}, 37 \%$ (Table 2 ), are similar to previous reports $(2,4)$ and suggest significant intersubject variability in $\mathrm{Ca}$ bioavailability. Neither $V_{a}$ nor $V_{o}$ were closely correlated to $V_{f}, V_{u}$, anthropometric parameters, or biochemical indices. The $r$ value of -0.40 for the relationship between $V_{f}$ and $V_{o}$ suggests that only $16 \%$ of the variability in $V_{o}$ was accounted for by variability in endogenous excretion. These relationships have not been assessed in previous studies.

Isotope methods using an extrinsically added tracer require the assumption that the tracer is adequately equilibrated in vivo with the native $\mathrm{Ca}$. Although this appears not to be completely the case in vitro for casein-bound $\mathrm{Ca}(26)$, this equilibration may occur in vivo within the gastrointestinal tract. Two recent studies have provided evidence that this may occur. Eastell et al. (15) demonstrated that $\mathrm{Ca}$ absorption in adults measured by dual tracer stable isotope studies is comparable to that obtained from mass balance. Liu et al. (27) showed that an extrinsic $\mathrm{Ca}$ tracer was absorbed similarly to an intrinsic $\mathrm{Ca}$ tracer in fortified human milk-fed premature infants.

Although our results support the use of high Ca-containing formulas to achieve in utero rates of Ca retention in LBW infants, they do not explain the etiology of the large intersubject variability in $\mathrm{Ca}$ retention. We suggest, however, that these variations represent true differences in the ability of LBW infants to absorb $\mathrm{Ca}$, the etiology of which may relate to as yet unidentified physiologic or hormonal factors. Although reports of fractures in LBW infants fed high mineral-containing formulas are rare (28), those caring for such infants must be aware that some infants (Table 1) will retain Ca well below in utero rates and may remain at risk for inadequate bone mineralization.

Acknowledgments. The authors thank the nursing and medical staffs at Holy Cross Hospital and Children's National Medical Center for their assistance with the balance studies; Marilea Miller, M.D., Anne Fletcher, M. D., and Richard Schanler, M.D. for their advice and assistance with this project; and Judith Abrams for preparing the mesh hammocks.

\section{REFERENCES}

1. Shenai JP, Reynolds JW, Babson SG 1980 Nutritional balance studies in verylow-birth-weight infants: enhanced nutrient retention rates by an experimental formula. Pediatrics 66:233-238

2. Rowe JC, Goetz CA, Carey DE, Horak E 1987 Achievement of in utero retention of calcium and phosphorus accompanied by high calcium excretion in very low birth weight infants fed a fortified formula. J Pediatr 110:581585

3. Schanler RJ, Abrams SA, Garza C 1988 Bioavailability of calcium and phosphorus in human milk fortifiers and formula for very low birth weight infants. J Pediatr 113:95-100

4. Cooke R, Hollis B, Conner C, Watson D, Werkman S, Chesney R 1990 Vitamin $\mathrm{D}$ and mineral metabolism in the very low birth weight infant receiving $400 \mathrm{IU}$ of vitamin D. J Pediatr $116: 423-428$

5. Wirth FH, Numerof B, Pleban P, Neylan MJ 1990 Effect of lactose on mineral absorption in preterm infants. J Pediatr 117:283-287

6. Uauy R, Waidelich D, Mize C 1989 Effects of phosphorus supply on balance at high calcium intakes in very low birth weight (VLBW) neonates. Pediatr Res 25:298A(abstr)

7. Huston RK, Reynolds JW, Jensen C, Buist NR 1983 Nutrient and mineral retention and vitamin $D$ absorption in low-birth-weight infants: effect of medium-chain triglycerides. Pediatrics 72:44-48 
8. Ehrenkranz RA, Gettner PA, Nelli CM 1989 Nutrient balance studies in premature infants fed premature formula or fortified preterm human milk. J Pediatr Gastroenterol Nutr 8:58-67

9. Barltrop D, Mole RH, Sutton A 1977 Absorption and endogenous faecal excretion of calcium by low birthweight infants of feeds with varying contents of calcium and phosphorus. Arch Dis Child 52:41-49

10. Greer FR, Tsang RC 1985 Calcium, phosphorus, magnesium, and vitamin D requirements for the preterm infant. In: Tsang $R C$ (ed) Vitamin and Minera Requirements in Preterm Infants. Marcel Dekker, Inc, New York, pp 99136

11. Aubert JP, Milhaud G 1960 Méthode de mesure des principales voies du métabolisme calcique chez l'homme. Biochim Biophys Acta 39:122-139

12. Aubert JP, Bronner F, Richelle LJ 1963 Quantitation of calcium metabolism: theory. J Clin Invest 42:885-897

13. DeGrazia JA, Ivanovich P, Fellows H, Rich C 1965 A double isotope method for measurement of intestinal absorption of calcium in man. $\mathrm{J} \mathrm{Lab} \mathrm{Clin} \mathrm{Med}$ 66:822-829

14. Hillman LS, Tack E, Covell DG, Vieira NE, Yergey AL 1988 Measurement of true calcium absorption in premature infants using intravenous ${ }^{46} \mathrm{Ca}$ and oral ${ }^{44} \mathrm{Ca}$. Pediatr Res 23:589-594

15. Eastell R, Viera NE, Yergey AL, Riggs BL 1989 One-day test using stable isotopes to measure true fractional calcium absorption. J Bone Min Res 4:463-468

16. Yergey AL, Vieira NE, Covell DG 1987 Direct measurement of dietary fractional absorption using calcium isotopic tracers. Biomed Environ Mass Spectrom 14:603-607

17. Abrams SA, Sidbury JB, Muenzer A, Esteban NV, Vieira NE, Yergey AL 1991 Stable isotopic measurement of endogenous fecal calcium excretion in children. J Pediatr Gastroenterol Nutr, in press
18. Weast RC (ed) 1988 CRC Handbook of Chemistry and Physics, 69th Ed. CRC Press Inc, Boca Raton, FL

19. Yergey AL, Hillman LS, Abrams SA, Vieira NE, Sidbury JB, Covell DG 1989 Calcium pool sizes correlate highly with bone growth in children. Pediatr Res 25:128A(abstr)

20. Moore LJ, Machlan LA, Lim MO, Yergey AL, Hansen JW 1985 Dynamics of calcium metabolism in infancy and childhood. I. Methodology and quantification in the infant. Pediatr Res 19.329-334

21. Yergey AL, Abrams SA, Vieira NE, Eastell R, Hillman AL, Covell DG 1990 Recent studies of human calcium metabolism using stable isotopic tracers. Can J Physiol Pharmacol 68:973-976

22. Zar JH 1984 Biostatistical Analysis, 2nd Ed. Prentice-Hall Inc., Englewood Cliffs, NJ, p 32

23. Yergey AL, Abrams SA, Vieira NE, Covell DG 1990 Compartmental analysis of calcium kinetics in premature infants suggests more rapid bone turnover than accretion. Pediatr Res 27:120A(abstr)

24. Heaney RP, Skillman RG 1964 Secretion and excretion of calcium by the human gastrointestinal tract. J Lab Clin Med 64:29-41

25. Senterre J 1975 Endogenous faecal calcium, total digestive juice calcium, net and true calcium absorption in premature infants. In: Zembera $Z$, Polacek K, Sabat V (eds) Perinatal Medicine: 4th European Congress of Perinata Medicine, Prague, Czechoslovakia, August 1974, pp 287-288

26. Abrams SA, Vieira NE, Yergey AL 1990 Unequal distribution of a stable isotopic calcium tracer between casein and whey fractions of infant formulas, human milk and cow's milk. J Nutr 120:1672-1676

27. Liu Y, Neal P, Ernst J, Weaver C, Rickard K, Smith DL, Lemons J 1989 Absorption of calcium and magnesium from fortified human milk by very low birth weight infants. Pediatr Res 25:496-502

28. Cooke RJ 1989 Rickets in a very low birth weight infant. J Pediatr Gastroenterol Nutr 9:397-399 